\title{
REFLEXÕES ACERCA DAS TECNOLOGIAS DIGITAIS E A FORMAÇÃO INICIAL DE PROFESSORES DE CIÊNCIAS BIOLÓGICAS.
}

\author{
Peterson Fernando Kepps da Silva ${ }^{1}$, LaVínia Schwantes ${ }^{1}$ \\ ${ }^{1}$ Universidade Federal do Rio Grande - FURG \\ <keppspeterson@gmail.com><laviniasch@gmail.com> \\ DOI: <https://doi.org/10.21439/conexoes.v14i4.1529>
}

\begin{abstract}
Resumo. As tecnologias digitais permitem que conteúdos sejam vistos e abordados por meio de hipertextos, animações e jogos educativos. Pensamos que estas tecnologias podem ser utilizadas na educação a fim de potencializar o trabalho docente e possibilitar a construção de atividades e práticas pedagógicas que promovam uma maior interação entre os estudantes, professor e o contexto social e tecnológico do qual fazem parte. Neste contexto, este trabalho objetiva discutir sobre as tecnologias digitais na formação de futuros professores de um curso de Ciências Biológicas Licenciatura (CBL). Para a produção de dados, desenvolvemos três perguntas sobre tecnologias digitais a serem aplicadas, por meio do aplicativo móvel Whatsapp, aos estudantes do curso de CBL de uma universidade federal. Buscamos com estes questionamentos perceber o que os alunos entendem sobre tecnologias digitais; se tiveram contato no período de graduação com assuntos concernentes às tecnologias; assim como as articulações que fazem entre a mesma e a educação. A análise foi feita por agrupamento das respostas semelhantes. Percebemos que a grande maioria dos investigados considera computador, celulares, vídeos, documentários, jogos, filmes e músicas como tecnologias digitais; estabelecem relação entre estas tecnologias e a escola; bem como não tiveram nenhum estudo sobre as tecnologias digitais durante a graduação.
\end{abstract}

Palavras-chaves: Tecnologias digitais. Formação inicial de professores. Ciências Biológicas Licenciatura.

\begin{abstract}
Digital technologies allow contents to be viewed and addressed through hypertexts, animations and educational games. It is thought that these technologies can be used in education to potentialize teachers work and allow activity building and pedagogical practices that promote a higher interaction between students, teachers and the social and technological context they belong to. Under these circumstances, this paper attempts to discuss digital technologies in the training of future teachers from the Bachelor of Biological Sciences (CBL). To produce data, we developed three questions about digital technologies to be applied through Whatsapp mobile application to students of the CBL course of a federal university. These questions were to perceive whether the students understand about digital technologies, if they had any contact with the subjects concerning technologies in the graduation period, as well as the articulations they make between it and education. The analysis was performed by the collection of similar answers. Results showed many of the subjects investigated consider computers, mobile phones, videos, documentaries, games, films and music as digital technologies; they establish a relation between these technologies and school. Moreover, none of them had no studies about digital technologies during graduation.
\end{abstract}

Keywords: Digital Technologies. Initial teacher training. Bachelor in Biological Sciences. 


\section{INTRODUÇÃO}

Tecnologias de Informação e Comunicação (TIC), Tecnologia digital, Tecnologias Digitais de Informação e Comunicação - TDICs, Tecnologias Digitais Interativas e Mídias Digitais são siglas ou termos que podem nos sugerir o uso da tecnologia; uma tecnologia "materializada", por exemplo, em dispositivos como telefones celulares (smartphones), terminal de agências bancárias, GPS e até mesmo nas urnas do sistema eleitoral brasileiro. Entretanto, essas siglas são constituídas a partir de campos de estudos das mais diferentes ordens, assim como pesquisas voltadas a discutir estas tecnologias por meio de seus impactos sociais, econômicos, ambientais e educacionais.

Considerando o contexto complexo, diverso e que nem sempre dialogam entre si, adotamos aqui o uso do termo tecnologias digitais, que incluem recursos digitais que "são elementos informatizados que permitem que conteúdos sejam abordados em materiais como imagens, vídeos, hipertextos, animações, simulações, páginas web, jogos educativos, dentre outros" (GARCIA et al., 2011, p. 82). Ainda neste sentido, pensamos que estas tecnologias digitais podem ser utilizadas na educação a fim de potencializar o trabalho docente e possibilitar a construção de atividades e práticas pedagógicas que promovam uma maior interação entre os estudantes, professor e o contexto social e tecnológico do qual fazem parte.

Discutir sobre as tecnologias digitais no campo educacional requer olharmos para a história e considerarmos o espaço que o método cartesiano ocupou (e ainda ocupa) em nossas vidas. A fragmentação do pensamento é fruto da ciência moderna (MORAES, 2003). A ciência, a partir do método, nos constitui enquanto sujeitos, influenciando na forma que vivemos e atuamos no meio social. Entretanto, passamos, nas últimas décadas, por intensas mudanças na sociedade. Neste sentido, a escola e o trabalho docente são desafiados a se adaptarem a elas e a buscarem, a partir de suas propostas pedagógicas e contextos, a construção de sujeitos cientes do meio em que vivem; assim como capazes de enfrentar e superar os problemas e desafios atuais.

Vivemos na atualidade tempos de mudanças constantes, rápidas e, como nos coloca Bauman (2001), fluidas. Esta noção de tempo situa a escola na zona do indeterminado; pois apesar destas transformações serem frequentes, a instituição escola - como local formal de aprendizagem - mantêm-se, ainda, com um forte vínculo na perspectiva moderna, permeada pela lógica disciplinar e alinhada com instrumentos (ou propostas) que, por vezes, não atendem os anseios e necessidades do tempo atual. Assim, nos colocamos aqui a pensar nas tecnologias digitais como ferramentas capazes de estreitar a relação entre as constantes transformações que hoje vivemos e o campo da educação. Além disso, podemos tomar as tecnologias digitais como ponto de partida para a construção de práticas pedagógicas mais conectadas aos instrumentos e meios utilizados pelos alunos.

Sobre esta situação, não podemos deixar de destacar que fatores como a precariedade da estrutura física de muitas escolas, a falta de tempo do professor para desenvolver diferentes propostas de trabalho e o pouco incentivo por parte do Estado no que concerne as tecnologias digitais podem, substancialmente, inviabilizar propostas de ensino que utilizem estas tecnologias. No entanto, para além dessas dificuldades (que são legitimas e reais), é importante considerarmos a formação dos futuros professores. Neste sentido, Garcia et al. (2011), colocam o quão significativo pode ser olhar o repertório dos profissionais da educação, a fim de “instrumentalizá-los para uma prática pedagógica fundamentada em um novo paradigma, diferente do tradicional, que mantêm distantes alunos e professores" (p. 80). Além disso, os autores sublinham que esta instrumentalização não se refere a um procedimento no qual capacitaria a escola com equipamentos técnicos, mas, sim, possibilitaria a reflexão e o pensamento crítico dos professores no que concerne ao uso e ao domínio das tecnologias digitais.

Pensemos na formação inicial dos profissionais da educação, isto é, nos cursos de licenciatura e na sua estrutura curricular. A reflexão e o pensamento crítico dos professores sobre tecnologias digitais fazem parte dos objetivos dos cursos de licenciaturas no Brasil? Ademais, qual o espaço que as tecnologias digitais ocupam nestes currículos? Os professores universitários desenvolvem propostas de ensino com os estudantes de licenciatura que visem explorar o uso de diferentes tecnologias digitais no contexto educacional? Os futuros professores se sentem motivados e/ou preparados para utilizar as tecnologias digitais em suas aulas?

Não temos as respostas para estas perguntas, mas entendemos que elas são importantes para elucidar ou nos levar a pensar - os rumos que estão sendo dados na formação de futuros professores no que tange às tecnologias digitais. A utilização destas tecnologias na educação passa, fundamentalmente, pelos professores, pois, para a construção de uma educação parametrizada nesta proposta de ensino, os profissionais da educação precisam estar dispostos a utilizarem as tecnologias de informação e comunicação; acreditar nas suas 
contribuições ao processo de ensino e aprendizagem, assim como superar possíveis estranhamentos no que concerne a substituição do trabalho docente pelas tecnologias digitais (ASSMANN, 2000).

Diante disso, este trabalho objetiva discutir sobre as tecnologias digitais na formação de futuros professores de um curso de Ciências Biológicas Licenciatura.

\section{CAMINHOS METODOLÓGICOS}

Para a produção de dados, desenvolvemos três perguntas sobre tecnologias digitais aplicadas a estudantes do curso de Ciências Biológicas Licenciatura (CBL). As perguntas realizadas foram:

\section{O que você entende por tecnologias digitais?}

2. Você estudou durante o período de graduação sobre tecnologias digitais?

3. Qual a sua opinião com relação as tecnologias digitais e sua utilização na escola?

Buscamos com estes questionamentos perceber o que os alunos entendem sobre tecnologias digitais; se tiveram contato no período de graduação com assuntos concernentes a este campo de estudo; assim como as articulações que fazem entre estas tecnologias e a educação. Além disso, escolhemos o curso de CBL de uma Universidade Federal situada no sul do estado do Rio Grande do Sul, primeiro, pela formação e atuação de dois dos autores deste artigo no ensino de Ciências e Biologia; segundo, por se tratar de um curso de graduação em licenciatura - o que vai ao encontro do objetivo desta pesquisa - discutir o uso das tecnologias digitais no período de formação inicial de professores.

A pesquisa foi realizada no ano de 2017 e os sujeitos participantes foram estudantes do sexto semestre do curso de CBL. Escolhemos este semestre pelos licenciandos já terem cursado $75 \%$ do curso - que possui um total de oito semestres; sendo os dois últimos destinados, principalmente, aos estágios supervisionados em escolas da rede básica de ensino.

Adotamos a perspectiva pós-crítica para a construção teórico-metodológica deste trabalho; o que nos possibilita construir e assumirmos diferentes metodologias ao longo do percurso. Entretanto, isto não significa dizer que as produções circunscritas por este viés não possuem rigor ou utilizam metodologias já existentes. Além disso, tomamos a liberdade de trilharmos o caminho que entendemos ser mais pertinente neste processo de investigação, o qual nos possibilitou elaborar e executar nosso trabalho de maneira a não seguir prescrições e modelos acabados de estratégias metodológicas. Assim como Corazza (2007), entendemos que não há uma metodologia padrão, na qual o trabalho de pesquisa, para se estabelecer enquanto produção científica, precisa ser construído e ancorado em uma base metodológica já existente.

Partindo deste princípio, organizamos nosso percurso investigativo em quatro etapas:

I. Elaboração das três perguntas referentes às tecnologias digitais (já expostas anteriormente);

II. Contato com um professor do sexto semestre do curso de CBL;

III. Após o contato com o professor de CBL, explicamos (de forma presencial e na aula deste professor) para os estudantes sobre a pesquisa e os convidamos para participarem de um grupo no aplicativo móvel (gratuito) de troca de mensagens instantâneas Whatsapp;

IV. Organização e análise dos dados.

A partir da netnografia (ou etnografia virtual), construímos este exercício de investigação por meio do aplicativo móvel Whatsapp. A netnografia, que é oriunda da etnografia, pode ser entendida "como um dos métodos qualitativos que amplia o leque epistemológico dos estudos em comunicação e cibercultura" (AMARAL, 2007. p. 35). Nesse sentido, buscamos aproveitar este espaço não físico constituído pelas redes digitais para desenvolvermos o ambiente de produção dos nossos dados.

Escolhemos trabalhar, nesta etapa da pesquisa, com a netnografia por entender que a mesma apresenta algumas potencialidades para a pesquisa, a saber:

a) Otimização do consumo de tempo - já que os estudantes escolhem o momento em que responderão os questionamentos realizados no grupo do aplicativo móvel Whatsapp;

b) Facilidade no acesso aos investigados, visto que encontrar um espaço físico e tempo para a aplicação das perguntas seria um fator limitante na pesquisa;

c) Facilidade no acesso à informação - tendo em vista que estes dados gerados online se deram de forma textual e, por isso, não precisam ser transcritos posteriormente; 
d) Informalidade no espaço de pesquisa - situação que minimiza algumas tensões que podem ser provocadas em pesquisas face a face, por exemplo; e) aproveitar ferramentas digitais, como o aplicativo móvel Whatsapp, para inserir as tecnologias digitais, também, nas pesquisas em educação.

O grupo no aplicativo Whatsapp se intitulou "BioTec" e as três perguntas (descritas anteriormente) foram postadas neste espaço. Os questionamentos foram postados um por vez com intervalos de até uma semana. Além disso, não interferimos nas respostas dos investigados o que, para Kozinets (2007) se configura por uma atuação não-obstrutiva e observacional. Decidimos colocarmos-nos mais próximo de um pesquisadorobservador do que um pesquisador-participante a fim de não interferirmos nas respostas dos estudantes.

Como os estudantes eram do mesmo semestre de CBL e já se conheciam, a apresentação inicial no grupo do aplicativo móvel ficou a encargo, principalmente, do pesquisador. Eles expuseram apenas seus nomes e idades, que pairam entre 21 e 24 anos.

Os alunos que se dispuseram a participar da pesquisa assinaram fisicamente um "termo de consentimento livre esclarecido", o qual explica o objetivo e a metodologia da pesquisa; esclarece que os dados produzidos (ou as perguntas respondidas no aplicativo móvel) a partir do grupo "BioTec" serão utilizados apenas para fins acadêmicos (artigos, livros, resumos); e que seus dados pessoais serão preservados, bem como o nome da universidade onde estudam. Por isso, os nomes que serão apresentados nas discussões deste trabalho são fictícios.

Com relação ao número de estudantes que participaram da pesquisa, inicialmente tínhamos quatorze alunos que integravam o grupo "BioTec" no aplicativo móvel; entretanto, dois alunos saíram do grupo antes mesmo de responderem o primeiro questionamento e outros cinco estudantes foram removidos do grupo por não responderam a primeira pergunta e, também, por não realizarem nenhum tipo de manifestação ao longo da primeira semana de investigação. Por isto, de um total de quatorze interessados inicialmente em participar da pesquisa, concluímos as três semanas de investigação com a participação de sete estudantes.

Embora não tenhamos grande abrangência no número de participantes, entendemos como de suma importância criar espaços para problematizar as tecnologias digitais no campo educacional; discutir o uso de suas potencialidades no processo de ensino e aprendizagem, assim como promover alguns apontamentos acerca da formação inicial de professores e as tecnologias digitais.

Tomando as respostas dos investigados como material de análise, buscamos perceber as compreensões e os entendimentos dos estudantes sobre as tecnologias digitais e a posição que possuem frente às mesmas com relação a sua utilização/aplicação na escola básica. Ademais, os dados foram agrupados e tabulados a partir das respostas semelhantes dos estudantes; já a escrita dos alunos do aplicativo móvel para este trabalho passou por uma correção gramatical. Porém, nenhuma palavra que poderia comprometer o sentido da frase foi alterada.

Além disso, as discussões e dados apresentados a seguir, são únicos; isto é, fazem parte de um contexto específico e localizado. Todavia, as experiências aqui apresentadas poderão se somar a outras e, assim, contribuir com a produção de conhecimentos no campo das tecnologias digitas articuladas a educação e formação inicial de professores.

\section{RESULTADOS E DISCUSSÃO}

Neste trabalho, discutiremos, inicialmente, a primeira pergunta, que buscou o entendimento dos estudantes de CBL acerca das tecnologias digitais. O fluxo geral das respostas apontou que elementos informatizados, como computador, celulares, vídeos, documentários, jogos, filmes e músicas são considerados como tecnologias digitais pelos estudantes. Além disso, eles fazem aproximações entre estas tecnologias e o campo educacional, embora o primeiro questionamento não tenha endossado intersecções neste sentido. Os excertos abaixo nos mostram a definição dada pelos estudantes a tecnologias digitais:

Flávia: "Quando falam em tecnologias digitais o que me vem a mente são: sites, aplicativos, vídeos; comunicação rápida e facilidade; a imagem (que se tornou a forma de ver e viver no mundo); jogos interativos; filmes; músicas, entre tantas outras coisas."

Elza: "Ao meu ponto de vista, eu acho que as tecnologias digitais são o acesso a informações de uma forma muito rápida pela internet, redes sociais, aplicativos; também existem documentários de fácil acesso, séries e jogos."

Carla: "Acredito que tecnologias digitais sejam todos os produtos oriundos da internet $\mathrm{e}$ os equipamentos que possibilitam o acesso 
a ela. Blogs, redes sociais, sites, serviços de streaming, smartphones, tablets, TV's smart, computadores, etc. Sendo todos objetos de propagação de informação e comunicação instantânea."

Lucas: "Celular, tablet, câmera, computador etc, são tecnologias digitais. Essas tecnologias possuem uma linguagem em comum que se expressa através de uma tela."

Além de citarem os elementos (ou as ferramentas) informatizados nos quais entendem como tecnologias digitais, os estudantes trazem a ideia de facilidade e acesso rápido a informação, como colocaram as estudantes Flávia, Elza e Carla. Neste sentido, pensamos que a presença das tecnologias digitais voltadas à comunicação está alterando a forma como nos comunicamos nos dias atuais. Estas tecnologias, além de possibilitarem novas formas de relação entre os sujeitos, alteram - do ponto de vista comunicacional - o conceito de emissor-receptor, no qual se dava pelo primeiro ser o transmissor da informação para o segundo (VALENTE 2014). O que se percebe hoje é a construção coletiva da informação ou uma maior participação dos sujeitos, seja por meio das redes sociais ou pela contribuição, por exemplo, de conteúdos como imagens e vídeos de um determinado acontecimento para os veículos de comunicação.

A comunicação apontada pelos estudantes pode ser articulada com a educação. A comunicação não se esgota nas produções de mídias, como as tradicionais televisiva e impressa; ela transcende estes espaços e meios, pois "o ato de comunicação em educação é um movimento entre pessoas que possuem em comum a vontade de ensinar e aprender" (KENSKI, 2008, p. 650). Além disso, a intersecção educação-comunicação, ou a comunicação com finalidade educacional, ultrapassa a utilização de equipamentos e se constitui a partir da necessidade de interlocução entre os sujeitos. Neste sentido, pensamos, a partir de Kenski (2008), que o ato comunicacional seja por meio da fala-escuta, sinais, movimentos corporais ou pelas próprias tecnologias digitais - tema de estudo desta pesquisa - está presente na escola e é capaz de contribuir com o processo de aprendizagem.

Podemos ampliar nossas discussões na medida em que os estudantes pontuaram, também, a facilidade promovida pelas tecnologias digitais. Como coloca a estudante Elza, a internet viabiliza o acesso e a utilização destas tecnologias. Em síntese, a rede mundial de computadores se coloca como um dos principais meios de comunicação de nossa época. Assim como o rádio, a televisão e o cinema tiveram momentos de evidência e vigência, hoje, a internet ocupa este espaço. O que não significa dizer que a mesma se sobrepôs aos meios aqui citados; pelo contrário, percebe-se a correlação entre eles, de modo que uns utilizam as especificidades e potencialidades dos outros; isto é, se relacionam e interagem de alguma forma.

Lado outro, as estudantes Flávia e Paula conferem interpretações, com relação às tecnologias digitais que abarcam efeitos negativos e regulação. Elas citam a importância de saber "dosar", isto é, controlar a utilização das tecnologias; assim como as relações de poder que podem ser intensificadas a partir de seu uso; e o individualismo entre os seres humanos. Isso é destacado nos excertos abaixo:

Flávia: “(...) Não que existam apenas coisas benéficas envolvendo as tecnologias digitais, acredito que quando mal utilizadas elas podem intensificar as relações de poder e o individualismo do ser humano. Tudo é uma questão de dose."

Paula: “(...) As tecnologias digitais além de facilitar também aproxima as coisas que acontecem no mundo, assim como aproxima as pessoas. Claro que como em tudo existe algum lado negativo, mas como já falaram, é uma questão de dose; saber utilizar o que veio para o bem."

Embora as estudantes não discorram sobre estes apontamentos, é importante pensarmos na condição na qual vivemos hoje. A sociedade de consumo, a partir de uma lógica de vida neoliberal, é marcada pela competição; o que, por sua vez, se articula com a construção de sujeitos individualistas (VEIGA-NETO, 2011). Pensemos, também, na intensificação de poder, ou no próprio poder dado em relação, como apontou Flávia. Que implicações seriam essas? O poder e controle de uns sobre os outros por meio das funcionalidades das tecnologias? A informação e o conhecimento como fonte de poder? Se discorrêssemos sobre estes questionamentos que nos acometeram a partir dos dados analisados, estaríamos conduzindo-nos para o campo das inferências. Entretanto, torna-se importante, ao menos neste momento, refletirmos acerca destas questões que fazem parte da realidade vigente.

Como mencionamos no início desta seção, os estudantes fizeram aproximações entre as tecnologias digitais e o campo educacional, mesmo que a primeira 
pergunta não denotasse estas articulações. Ao responderem o questionamento desta maneira, os investigados nos mostram que estabelecem relações entre estas tecnologias e a educação. Neste sentido, destacamos as estudantes Flávia e Elza. A primeira sublinha o uso das tecnologias digitais em sala de aula; se coloca sabedora do "básico" no que concerne às tecnologias e questiona o que se pode fazer para a utilização das mesmas no espaço escolar. A segunda, também destaca o uso das tecnologias no ambiente escolar, a sua capacidade de aproximar a relação entre professor e alunos; bem como realça instituições escolares que, por vezes, proíbem o acesso dos estudantes às tecnologias digitais.

Flávia: “(...) Quando falamos das metodologias que utilizamos em sala de aula, as tecnologias digitais, estão sempre presentes. Muitas vezes, essa é a única linguagem que pode realmente fazer com que professor e estudante se entendam. Eu particularmente, mesmo sabendo o básico de qualquer coisa do tipo, sou a favor do uso de ferramentas digitais em sala de aula. Uma pergunta típica que nos fazem na graduação é: e se na escola em que você der aula não tiver isso (internet ou projetor na maioria das vezes)? Eu não sei, eles falam tanto que temos que fazer com que a escola passe do século XX para o século XXI e ainda são capazes de fazer esta pergunta. Se fosse para fazer algum tipo de pergunta certa seria: o que nós podemos fazer para que na nossa escola seja possível utilizar as tecnologias digitais? Como vamos nos organizar para lutar por um espaço escolar mais equipado? Enfim, é isso que acredito."

Elza: “(...) Acredito que todas essas formas de tecnologia digitais (internet, redes sociais, aplicativos, documentários, séries e jogos) podem ser utilizadas no momento da elaboração de aulas e nas próprias aulas, para levantar problemáticas do nosso dia a dia. Acho também que isso acaba aproximando os estudantes dos professores, se tu conhece o linguajar, os "memes", os assuntos que eles utilizam nessas redes fica mais fácil acontecer uma interação. Porém, nem sempre é possível utilizar desses meios, pois algumas escolas até proíbem ou os estudantes não têm acesso a essas tecnologias."

Aproveitar as funcionalidades das tecnologias digitais na prática educacional e trabalho docente é um dos desafios que a sociedade e as instituições de ensino vivenciam atualmente (BITTENCOURT; ALBINO 2017). Os autores consideram que a falta de conhecimento pode ser um dos fatores que levam a não utilização de forma adequada das tecnologias no processo de ensino e aprendizagem. Neste cenário, pensamos na resposta da estudante Flávia, quando coloca saber o "básico de qualquer coisa do tipo". A possível familiarização dos nativos digitais com relação às tecnologias não necessariamente se reflete no seu uso produtivo no espaço escolar. Em outras palavras, embora os estudantes que participaram desta pesquisa possam ser considerados nativos digitais, pois possuem idades entre 21 e 24 anos - e teoricamente teriam mais desenvoltura e proximidade com as tecnologias digitais - o uso da mesma no espaço escolar (ou nas aulas destes professores de Ciências e Biologia em formação inicial) não está assegurado, como os investigados mesmo apontaram; bem como a sua exploração didática e pedagógica nas atividades de sala de aula; e o conhecimento acerca destas tecnologias.

No que se refere a instituição escola e práticas/metodologias de ensino, entendemos que é preciso uma formação para tal. A partir de objetivos e propostas pedagógicas é que o professor se instrumentaliza no sentido de preparo enquanto profissional da área para o exercício do trabalho docente. Para incorporar as tecnologias às práticas pedagógicas na educação básica necessita-se de certa familiaridade com as mesmas e o envolvimento de elementos como "recursos tecnológicos, alunos e professores, o espaço e a gestão escolar, questões políticas e econômicas" (LOPES; QUEIROZ et al. 2014). Além disso, se faz necessário olhar, também, a formação inicial de professores.

A maneira que os professores aprendem durante o período de sua formação inicial pode refletir nos modos (ou meios) que ele irá utilizar para ensinar. Por esse ângulo, é importante que as graduações em licenciatura mostrem e utilizem as tecnologias digitais na universidade; não apenas de maneira expositiva, na qual instrumentos como multimídia e slides se tornam reprodutores de textos digitalizados. Entendemos que os estudantes de licenciaturas precisam interagir e atuar sobre e com as tecnologias, por meio de pesquisas, reflexão e interpretação. A partir deste contato, que está para além do uso do multimídia/slides como mero substituto da lousa, a construção de conhecimento pode ser promovida com maior dinamicidade e mais próxima deste tempo, que é marcado pelo surgimento constante de instrumentos digitais.

Decerto, não pretendemos desconsiderar nenhuma 
metodologia ou forma de ensino, bem como situar as tecnologias digitais em uma posição na qual se mostra como o melhor modo de aprendizagem a ser utilizado pelos profissionais da educação. Longe disso. Existe um movimento de muitos autores questionando pontos que consideram negativos a respeito da utilização das tecnologias na vida dos sujeitos, como a dificuldade nos relacionamentos interpessoais.

Seguindo as discussões aqui propostas, destacamos as colocações da estudante Elza, na qual coloca que "nem sempre é possível utilizar desses meios, pois algumas escolas até proíbem ou os estudantes não têm acesso a essas tecnologias". Sobre isso, é importante atentarmos para duas questões. A internet, como meio de acesso de muitos recursos digitais (vídeos, hipertextos, animações, simulações, páginas web, jogos) não está disponível a todos. Segundo dados do Instituto Brasileiro de Geografia e Estatística - IBGE (2017), aproximadamente $63 \%$ dos domicílios têm acesso à internet. Além disso, em 2016 a internet estava presente em $63,6 \%$ dos lares e em $94,8 \%$ deles havia celulares sendo usados para se conectar à rede (IBGE, 2017). Podemos pensar que a internet disponível a partir de chip de celulares impõe limites quanto ao acesso a todas as potencialidades da rede.

A segunda questão se dá pela proibição das escolas ao uso das tecnologias digitais por parte dos estudantes. Embora a investigada Elza apenas aponte tal proibição, estudos articulam esta restrição com o receio que os profissionais da educação possuem com as tecnologias digitais. Estamos passando por uma mudança na circulação dos saberes; isto é, outros espaços, além da escola e da biblioteca, também se tornaram fontes de conhecimento. Diante disso, "muitas vezes os docentes adotam uma posição defensiva e às vezes até negativa, no que se refere às mídias e às tecnologias digitais, como se pudessem deter seu impacto e afirmar o lugar da escola e o seu como detentores do saber" (FREITAS 2010, p. 341). Neste contexto, entendemos que os profissionais da educação não serão substituídos pelas tecnologias digitais, mas, sim, terão mais uma ferramenta para interagir e ampliar as possibilidades pedagógicas; o que implica em uma "nova" tarefa: aprender a utilizar as tecnologias digitais como instrumento do trabalho docente.

Assim como alguns participantes da pesquisa, a estudante Aline aponta elementos informatizados como celular, data show, laboratórios de informática, televisão como tecnologias digitais e os aproxima do sistema educativo; já a Laura faz articulações com acesso rápido e praticidade - o que também pode ser percebido nas respostas de certos investigados. Além disso, ambas trazem apontamentos no que se refere à utilização destas tecnologias:

Aline: "Entendo que são todas as coisas digitais que podemos usar como material didático. Como celular, data show, laboratórios de informática, televisão e até mesmo som. Contudo, acho que são usados de forma errônea, monótona e tradicional; acho que quando temos essas tecnologias à disposição precisamos pensar na melhor forma de utilizá-las, de que forma vai atingir aos nossos estudantes."

Laura: "Penso em tecnologia como algo rápido e prático, no qual tem a capacidade de conectar as pessoas e facilitar o ensino. Acredito que se for usada a favor da educação ela traz muito benefícios para ambas as partes, porém muitas pessoas veem esse artefato como algo usado apenas para lazer."

Pensamos que as expressões "forma errônea", "tradicional", "monótona" e "artefato como algo usado apenas para lazer", no que se refere ao uso das tecnologias digitais na educação, podem ser vinculadas a estrutura curricular dos cursos de licenciatura. Neste sentido, apresentamos de forma sintética os resultados encontrados na pesquisa de Gatti e Barreto (2009), que buscou "oferecer um balanço da situação relativa à formação de professores para a educação básica no Brasil" (p. 13). Dentre outras questões, o trabalho das autoras analisou a estrutura curricular e as ementas de 165 cursos presenciais de instituições de ensino superior do território brasileiro que oferecem "formação inicial de docentes nas áreas de Pedagogia, Letras: Língua Portuguesa, Matemática e Ciências Biológicas" (IDEM, p. 117). Em relação ao curso de Ciências Biológicas, que ao todo foram analisados 31 cursos de licenciatura, os resultados indicam que há um predomínio dos conteúdos/disciplinas da área das Ciências Biológicas e, as disciplinas relativas ao campo da educação e docência, se apresentam em baixo número (GATTI; BARRETO, 2009).

Entendemos que este baixo número de disciplinas que focalizam a educação nos cursos de licenciatura podem estar entrelaçados com o não desenvolvimento de assuntos específicos como as tecnologias digitais no campo educacional. Diante disso, apresentamos os dados da segunda pergunta realizada aos estudantes de CBL: "você estudou durante o período de graduação sobre tecnologias digitais?": 
Ana: "Lembro de algumas professoras terem comentado alguma coisa sobre as tecnologias digitais neste ano, mas não foi nada muito aprofundado. Não me lembro de ter visto durante a graduação."

Flávia: "Bom, não vimos muitas coisas sobre tecnologias digitais no curso como um todo, mas esse ano a professora trouxe um aluno para falar da utilização do celular em sala de aula. Achei uma proposta bem interessante; e acredito que deveria ter mais coisas do tipo, pois nós passamos quatro anos aqui e poucas coisas são faladas e trabalhadas sobre esta questão."

Paula: "Durante nosso curso não vimos muito sobre tecnologias digitais; na verdade somente as professoras das disciplinas de educação que tem a preocupação de trazer alguma coisa sobre tecnologias para nós, mas é somente nestas disciplinas mesmo."

As respostas das estudantes Ana, Flávia e Paula elucidam como as tecnologias digitais estão sendo exploradas no curso de CBL investigado. Neste sentido, nos parece que os processos iniciais formativos de professores ainda se mostram de forma tímida com relação à exploração do uso das tecnologias digitais na educação. Dizemos isso tanto pelos dados da pesquisa de Gatti e Barreto (2009) - que do total de horas das disciplinas obrigatórias relacionadas aos conhecimentos específicos para a docência, $0,2 \%$ se referem aos saberes ligados à tecnologia - quanto pelas informações dos alunos aqui investigados. Embora uma análise curricular fuja do escopo do nosso trabalho, entendemos que não há um investimento com relação ao uso destas tecnologias especificamente. Como a estudante Paula destacou: "as professoras das disciplinas de educação que tem a preocupação de trazer alguma coisa sobre tecnologias para nós". Entretanto, cabe lembrar que em um curso de licenciatura todas as disciplinas precisam estar concatenadas a formar professores - não apenas as tidas como "pedagógicas" ou da "educação".

Continuando as discussões, apresentamos as respostas da terceira e última pergunta realizada aos estudantes de CBL: "qual a sua opinião com relação às tecnologias digitais e sua utilização na escola?”. Entendemos que as respostas dos excertos abaixo podem ser articuladas, pois se complementam, na medida em que demarcam: o auxílio que as tecnologias digitais podem trazer para o sistema educativo; as aproximações entre professores e alunos; e a importância dos professores uti- lizarem e orientarem o uso destas tecnologias, fazendo com que as mesmas auxiliem no ensino e tornem as aulas mais atrativas.

Carla: "Acho que as tecnologias digitais não devem serem vistas como um empecilho para a função do professor na sala de aula, e sim, como um auxílio ao processo de ensinoaprendizagem. Se elas fazem parte do nosso cotidiano, por que não fazer parte também da sala de aula? Aproximando mais a escola a realidade do estudante. Cabe aos professores orientar o uso das mesmas de forma que auxilie no ensino."

Paula: "Acredito que as tecnologias digitais estão aí para nos auxiliar, tornar as coisas mais fácies e com certeza o uso destas podem ajudar muito na escola, para dar as aulas e acaba também aproximando alunos e professores, já que hoje em dia os alunos estão cada vez mais ligados às novas tecnologias e nós como professores temos que aproveitar disso para tornar as aulas mais atrativas."

Elza: "Acho que é sempre válido a utilização, seja na sala de aula ou na preparação das aulas. Acredito que estando "antenados"no que está rolando em relação as tecnologias, facilita tanto a aproximação estudante professor, quanto aproxima da realidade dos estudantes."

As respostas das estudantes Carla, Paula e Elza resumem as colocações de todos os outros quatro investigados com relação ao uso destas tecnologias na escola. Por isso, podemos indicar que não há a presença de disciplinas ou de discussões ampliadas sobre tecnologias no curso de CBL dos estudantes analisados. Neste sentido, a análise das respostas são ainda mais eloquentes para dizermos que estes futuros professores e professoras não estão sendo preparados e/ou estimulados para a utilização dos recursos tecnológicos na prática docente.

Diante desses dados e das análises apresentadas, percebemos que a formação inicial de professores de CBL ainda não exploram as tecnologias digitais no campo educacional. Pesquisas como a de Gatti e Barreto (2009) nos mostram que este cenário não se restringe ao curso de Ciências Biológicas investigado, mas a diferentes outros cursos de licenciaturas, como Letras, Matemática e Pedagogia. Os conhecimentos atrelados à tecnologia, ainda conforme os autores supracitados, são raros, tendo em vista que na maior parte dos currículos há o predomínio da formação disciplinar específica. 
REFLEXÕES ACERCA DAS TECNOLOGIAS DIGITAIS E A FORMAÇÃO INICIAL DE PROFESSORES DE CIÊNCIAS BIOLÓGICAS.

\section{CONSIDERAÇÕES FINAIS}

Retomando as discussões realizadas, percebemos que a grande maioria dos investigados consideram elementos informatizados: computador, celulares, vídeos, documentários, jogos, filmes e músicas como tecnologias digitais; e estabelecem relação entre estas tecnologias e a escola - mesmo quando não são questionados sobre esta intersecção. Além disso, os estudantes demarcam que não tiveram nenhum estudo amplo sobre as tecnologias digitais na educação, mas, sim, alguns professores específicos das disciplinas pedagógicas buscaram traçar articulações neste sentido.

Encaramos estes dados com certa preocupação, pois como os futuros professores irão utilizar as tecnologias digitais na educação e fazer delas instrumentos para atender as novas demandas da sociedade se as mesmas não são exploradas desde a formação inicial? Como já discutimos anteriormente, entendemos que é a partir de propostas pedagógicas que o professor se instrumentaliza e capacita para desenvolver seu trabalho. Ademais, percebemos que as intersecções entre educação e tecnologias digitais estão à margem do curso de CBL investigado, pois os estudantes marcam esta ausência, bem como a tentativa de apenas alguns professores do curso buscarem inserir a temática, ainda que de forma não "aprofundada".

Outra reflexão que se impõe diante das discussões realizadas é por que aproximar as tecnologias digitais do contexto das licenciaturas? Se as novas tecnologias fazem parte da realidade de muitos alunos e estão presentes na sociedade, bem como ocupam papel de destaque; é preciso, então, começar a reconhecer a importância destas e inseri-las no processo de formação inicial de professores. Inseri-las de modo a construir tanto um aprendizado técnico; isto é, saber utilizar de forma prática estas ferramentas no campo educacional quanto crítico, a fim de compreender que os conhecimentos na contemporaneidade (estejam eles ancorados nas tecnologias digitais ou não) são fluidos e provisórios.

\section{REFERÊNCIAS}

AMARAL, A. Categorização dos gêneros musicais na internet-para uma etnografia virtual das práticas comunicacionais na plataforma social last. fm. Novos rumos da cultura da mídia. Indústrias, produtos e audiências. Rio de Janeiro: Mauad, v. 1, p. 227-242, 2007.

ASSMANN, H. A metamorfose do aprender na sociedade da informação. Ciência da informação, SciELO Brasil, v. 29, n. 2, p. 07-15, 2000.
BAUMAN, Z. Modernidade líquida. 1. ed. Rio de Janeiro: Jorge Zahar, 2001. 280 p.

BITTENCOURT, P. A. S.; ALBINO, J. P. O uso das tecnologias digitais na educação do século xxi. Revista Ibero-Americana de estudos em educação, v. 12, n. 1, p. 205-214, 2017.

CORAZZA, S. M. Labirintos da pesquisa, diante dos ferrolhos. In: COSTA, M. V. (Ed.). Caminhos investigativos: novos olhares na pesquisa em educação. Rio de Janeiro: Lamparina editora, 2007.

FREITAS, M. T. Letramento digital e formação de professores. Educação em Revista, SciELO Brasil, v. 26, n. 3, p. 335-352, 2010.

GARCIA, M. F.; RABELO, D. F.; SILVA, D. da; AMARAL, S. F. do. Novas competências docentes frente às tecnologias digitais interativas. Teoria $\mathbf{e}$ Prática da Educação, v. 14, n. 1, p. 79-87, 2011.

GATTI, B. A.; BARRETO, E. S. D. S. Professores do Brasil: impasses e desafios. 1. ed. Brasília: Unesco, 2009.

IBGE. Pesquisa Nacional por Amostra de Domicílios - PNAD. 2017. Disponível em: <https://www.ibge.gov.br/estatisticas-novoportal/ multidominio/ciencia-tecnologia-e-inovacao/ 9127-pesquisa-nacional-por-amostra-de-domicilios. html?\&t=resultados $>$ Acesso em: 25 nov. 2017.

KENSKI, V. M. Educação e comunicação: interconexões e convergências. Educação \& Sociedade, SciELO Brasil, v. 29, n. 104, p. 647-665, 2008.

KOZINETS, R. V. Netnography 2.0. In: BELK, R. W. (Ed.). Handbook of Qualitative Research Methods in Marketing. Toronto, Canadá, 2007. p. 129.

LOPES, P. M. A.; QUEIROZ, M. d. F. A. de et al. O uso das tecnologias digitais em educação: seguindo um fenômeno em construção. Psicologia da Educação, v. 38, n. 1, p. 49-61, 2014.

MORAES, M. C. Educar na biologia do amor e da solidariedade. 1. ed. Petrópolis: Editora Vozes, 2003.

VALENTE, J. A. A comunicação e a educação baseada no uso das tecnologias digitais de informação e comunicação. UNIFESO-Humanas e Sociais, v. 1, n. 1, p. 141-166, 2014. 
REFLEXÕES ACERCA DAS TECNOLOGIAS DIGITAIS E A FORMAÇÃO INICIAL DE PROFESSORES DE CIÊNCIAS BIOLÓGICAS. VEIGA-NETO, A. Governamentalidades, neoliberalismo e educação. In: BRANCO, G. C.;

VEIGA-NETO, A. (Ed.). Foucault: filosofia \&

política. Belo Horizonte: Autêntica Editora, 2011. 